\title{
Integración regional y actores subnacionales. El caso del Mercosur ${ }^{1}$ Regional integration and sub-national actors: Mercosur's case Mercedes Botto
}

\author{
Mercedes Botto es investigadora principal del \\ Consejo Nacional de Investigaciones Científicas y \\ Técnicas y docente de la Facultad Latinoamericana de \\ Ciencias Sociales, Argentina. \\ E-mail: mbotto@flacso.org.ar
}

\section{resumen}

La decisión de los gobiernos nacionales de integrarse y derribar fronteras genera cambios en los gobiernos subnacionales y constituye una ventana de oportunidad para que ellos aumenten su autonomía en la gestión internacional vis a vis los Estados centrales. Sin embargo, como lo demuestra este artículo, la posibilidad de convertir este desafío en una oportunidad o en un problema dependerá de la modalidad y alcance de los procesos de integración, por una parte; y de la ubicación geográfica y el perfil productivo de cada provincia, por el otro.

Con respecto al primero, el artículo identifica dos tipos de los incentivos: los directos y formales, como ser los canales de participación y los recursos que proveen los gobiernos del bloque a los actores subnacionales; y los incentivos indirectos e informales, que por oposición a los primeros, derivan de la acción de los mercados y no de los Estados. E1 Mercosur es un caso híbrido a este respecto: si bien estamos frente a un procesos de apertura creciente de espacios y recursos a nivel nacional, la lógica que impera su dinámica y distribución sigue estando en manos de las burocracias nacionales y desincentiva la acción colectiva de carácter horizontal y transnacional, la que en definitiva sigue siendo motorizada por los mercados y reducida a aquellas provincias con mayores ventajas comparadas.

\section{summary}

The decision of national governments to integrate and break down boundaries generates changes in subnational governments and it's a window of opportunity for them to increase their international management autonomy vis a vis the Central States. However, as shown by this article, the ability to turn this challenge into an opportunity or a problem will depend on the type and scope of integration processes on the one hand, and the geographic location and the production profile of each province, on the other.

The article identifies two types of incentives: the direct and formal, such as participation channels and resources that provide EU governments subnational actors, and indirect incentives and informal, that in contrast to the first, from the action of markets and states. Mercosur is a hybrid case in this regard: while we are facing an increasingly open process space and resources at the national level logic prevailing dynamics and distribution remains in the hands of national bureaucracies and discourages collective action horizontal and crime, which ultimately is still powered by the markets and reduced major advantages compared those provinces. palabras clave

integración regional subnacional / Mercosur keywords

sub-national integration / Mercosur 


\section{Introducción}

En los años noventa hubo una abundante producción de artículos sobre el proceso de internacionalización de los Estados subnacionales en la Argentina. Se entendía por internacionalización a los procesos de creación de capacidades autónomas de vinculación externa e inserción internacional, respecto al Estado nacional, que había sido el responsable exclusivo de la diplomacia hasta ese entonces. A tono con el paradigma ideológico del momento, las actividades de los actores subnacionales se centraron en las negociaciones económicas, como la promoción de exportaciones, la atracción de inversiones y créditos y la cooperación técnica. ${ }^{2}$

La discusión académica estuvo centrada alrededor de dos interrogantes principales: el primero, vinculado a los factores y a las condiciones que favorecen este proceso de internacionalización subnacional; y el segundo, vinculado a los alcances y a los diseños institucionales que adquieren estas nuevas capacidades en las provincias argentinas. Respecto al primero, la literatura identifica factores externos de alcance global y regional -a saber, la creciente interdependencia económica, la emergencia de nuevos poderes globales y los procesos de integración regional-y otros factores domésticos, propios y peculiares a cada Estado nacional. Si bien el mapeo fue amplio, la producción académica en la Argentina se focalizó sobre estos últimos y en ellos primó el debate sobre los impactos que la reforma constitucional de 1994 conllevó sobre los marcos legales e institucionales en cada una de las provincias. ${ }^{3}$

En este artículo proponemos volcar la mirada del plano nacional al regional, respondiendo a la pregunta ¿en qué medida la integración regional, que logra su perfil más acabado con el Mercosur (1991), contribuyó al proceso de internacionalización subnacional? Con esta pregunta de investigación buscamos al menos dos objetivos. En primer lugar, contribuir al debate prexistente, que como vimos anteriormente, no se ha detenido mayormente a profundizar los impactos de las variables exógenas sobre la creación de capacidades subnacionales. En segundo lugar, aportar elementos para la discusión de índole político y normativo que ha venido sobrevolando el proceso de internacionalización subnacional entre dos visiones polarizadas, por un lado aquellos que defienden la idea de que la autonomía subnacional perjudica la cohesión del Estado nacional (Bertanou, 2008) y por el otro, aquellos que consideran que la fortalece (Russell, 2010, entre otros).

Para ello se analizan y comparan los efectos que el Mercosur ha conllevado a un grupo de provincias argentinas que comparten la frontera física con países miembros del bloque - como son las provincias de Chaco y Corrientes- $y$ otras que son parte del principal corredor comercial del Mercosur, las provincias de Buenos Aires, Córdoba y Santa Fe. La conclusión a la que llegamos señala que la creación del Mercosur significó, como todo proceso de integración regional, una ventana de oportunidad para la creación de nuevas capacidades de vinculación autónoma con actores del exterior. Pero como demuestra la comparación con otros casos y la evidencia recogida en el trabajo de campo, no todos los procesos de integración abren las mismas ventanas ni tampoco las provincias ubicadas en la frontera obtienen los mismos beneficios de la integración regional. En este caso, los alcances se 
han visto en gran medida reducidos por el carácter intergubernamental del proceso integracionista que mantienen los espacios y recursos regionales bajo el control de las burocracias nacionales, por una parte; y por el perfil productivo y exportador de cada provincia, lo que en definitiva determina la capacidad y autonomía para la proyección internacional de manera individual. Dentro de estos factores domésticos, es importante agregar las características personales de los gobernadores y su equipo de asesores y funcionarios.

El trabajo está dividido en tres partes. En la primera se analizan los aportes y contribuciones de la literatura al tema, tanto en sus abordajes teóricos como de la casuística acumulada por otros procesos de integración regional. En la segunda parte se caracteriza el proceso de activación promovido por el Mercosur en términos de canales y recursos abiertos a las provincias y actores subnacionales. En la tercera y última parte, se analizan y comparan las distintas estrategias de internacionalización seguidas por las provincias seleccionadas, identificando y comparando sus resultados en términos del tipo y número de redes creadas a partir del proceso de integración regional. ${ }^{4}$

\section{1. ¿Existe un vínculo ineludible entre integración regional y autonomía local?}

La pregunta acerca de la existencia o no de un vínculo entre la integración regional y la descentralización subnacional no es fácil de responder. Su respuesta ha ido cambiando con el tiempo y estuvo durante muchos años centrada sobre la experiencia de la Unión Europea. En los ochenta, por ejemplo, se preveía que la creación de instituciones supranacionales debilitaría o inhibiría el impulso hacia las autonomías regionales al futuro. Hoy, en cambio, existe una gran diversidad de opiniones a este respecto y muchos autores demuestran que la integración regional lejos de acallar las voces locales, las ha fortalecido en los hechos (Kaiser, 2005; Aldecoa Luzurraga, 2009; Noferini, 2010, entre otros). ${ }^{5}$

Esta afirmación se extiende inclusive al vínculo entre los Estados nacionales y sus subregiones. Autores como Nagel (2001, citado por Noferini, 2010) y Blanes Salas (2010) señalan que la supranacionalidad ha logrado convertir una relación naturalmente conflictiva -como es la puja por el manejo exclusivo de la diplomacia- en una relación de suma positiva, en la cual los Estados con tradición y prácticas federales son los que mayor ventaja sacan de la supranacionalidad, ya que ven ampliada su participación en nuevos espacios europeos y además consolidan la cohesión nacional a través de la representación de sus propias subregiones como portavoces de la nación en los foros de decisión y debate europeos.

En la actualidad esta discusión excede los límites del debate europeo y de la teoría de la gobernanza multinivel cuyos presupuestos son difíciles de encontrar en otros contextos ${ }^{6}$; y se extiende a la experiencia de otros bloques regionales y de nuevos enfoques analíticos, como el de la paradiplomacia, oriunda de las disciplinas sociales como las relaciones internacionales; y la teoría del escalamiento geográfico, vinculada con la antropología y otras disciplinas humanas. Sin embargo, todas ellas -inclusive la teoría de la gobernanza multinivel- hablan de 
la existencia de un vínculo necesario entre integración regional y autonomía subnacional y señalan que la primera favorece a la internacionalización de los actores subnacionales (Hocking, 2000).

Las diferencias entre las distintas teorías y enfoques se vuelven a plantear en términos de la problemática de interés, de la unidad de análisis y de los aportes y hallazgos con que contribuyen a nuestro interrogante. Mientras los estudios de la paradiplomacia focalizan la mirada sobre el problema del vínculo (competencia o cooperación) que se genera entre los distintos niveles de Estado (nacional y subnacional) a lo largo del desarrollo y evolución histórica; los enfoques del escalonamiento, centran su análisis en las sinergias generadas a ambos lados de la frontera. En este sentido, su unidad de análisis no es la provincia, como por lo general ocurre en los enfoques de la paradiplomacia, sino en las ciudades hermanadas, porque ellas son un escenario privilegiado para observar los cambios generados por la integración regional. Es justamente en estos "espacios transfronterizos" -que ayer estaban separados por fronteras de distinta índole- y que hoy día están integrados por la decisión de hacerlas desaparecer donde surgen nuevos objetivos estratégicos y nuevas fuerzas sociales (Jessop, 2002).

El enfoque del escalonamiento se ocupa de identificar y analizar estas nuevas formas de acción colectiva, roles y capacidades surgidas en estos espacios transfronterizos y una de las conclusiones importantes a la que llega es que no existe una única forma de gobernanza subnacional sino que ella varía de bloque en bloque, en gran medida determinada por el contexto institucional en el que está enmarcado cada proceso (Pekerman, 2005). El autor identifica tres modelos de gobernanza subnacional, representada por los casos paradigmáticos de la UE, el NAFTA y el ASEAN: en cada uno de ellos el tipo de redes que prevalece, el liderazgo y la motivación de la acción colectiva va variando.

A grandes rasgos, la UE se caracteriza como un modelo de gobernanza administrativa promovida desde instancias supranacionales. Se trata de una mezcla de redes horizontales que involucran a autoridades locales con redes verticales que comprenden altas autoridades (gobiernos centrales y la Comisión Europea). Entre ambos tipos de redes existe una profunda interconexión: mientras que las primeras se encargan de la implementación y ejecución de los proyectos fronterizos; la red vertical desarrolla un papel de motivador (incentivos) y de coordinación (inteligencia descentralizada). La acción colectiva subnacional está liderada por actores públicos mientras los privados tienden a ocupar un rol subalterno. ${ }^{7}$ Los temas o motivaciones que dan origen a estas redes locales y regionales son variados e involucran a los distintos temas de la agenda pública.

El modelo norteamericano está en las antípodas del anterior. En este caso, el activismo subnacional está motivado por la acción de los mercados y atracción de la economía estadounidense en búsqueda del abaratamiento de los costos de producción. Esta nueva dinámica transfronteriza genera problemas y demandas de responsabilidades pública y de legitimación política, cuya solución no viene de los Estados nacionales o regionales sino de redes y de foros transfronterizos. ${ }^{8} \mathrm{La}$ acción colectiva en áreas de frontera es descrita como una gobernanza fragmentada 
en la cual la cooperación colectiva involucra tan solo a actores locales, públicos y privados, de ambos lados de la frontera. Se trata de redes o coaliciones fragmentadas motivadas por intereses y temas particularistas en donde el sector privado -empresas y think tanks - tienen el liderazgo. Entre estas redes, y a diferencia del caso europeo, no existe mayor coordinación (Clarke, 2000) y la visión que unifica esta estrategia colectiva es exclusivamente económica: la de crear un espacio económico homogéneo que supere las desventajas asociadas a la localización de frontera.

Por último, el modelo o paradigma de gobernanza transfronterizo del este asiático asemeja al NAFTA en términos de la motivación: lo que estas áreas buscan es la complementariedad económica a través de las llamadas zonas económicas especiales. ${ }^{9}$ Sin embargo, se diferencia del modelo de NAFTA en términos de la construcción de gobernanza: estas redes fronterizas actúan bajo una fuerte coordinación interestatal entre agencias a nivel nacional, articulando a autoridades locales (ejemplo, el triángulo de Indonesia, Malasia y Singapur) o bien a redes débilmente entrelazadas de actores públicos y privados (como sucede en el triángulo de la Gran China).

En cuanto a las contribuciones de la Paradiplomacia a nuestra investigación encontramos, en primer lugar, la identificación de los nuevos actores locales -públicos y privados- que ejercen funciones de diplomacia y de networking internacional que antes estaban en manos exclusivas de la burocracia y funcionarios nacionales. En segundo lugar, la identificación y análisis de los distintos impactos que esta nueva forma de diplomacia genera sobre la nación, en términos de coherencia de la gestión externa de un país y de la cohesión interna entre los Estados subnacionales (Zubelzú 2008; Keating, 2000; Criekemans, 2010; Russell, 2010; Lachapelle \& Paquin, 2011, entre otros).

Sobre el primero de estos impactos, los estudiosos advierten que la proliferación y participación de nuevos actores e intereses en las negociaciones económicas internacionales tienden a aumentar los problemas de coordinación y a aumentar las posibilidades de superposición y competencia entre las distintas esferas o niveles del Estado (Jordana et al., 2010). En cuanto al impacto sobre la cohesión interna, se señala que la autonomía o descentralización de la gestión internacional fomenta la fragmentación y el aumento de las asimetrías internas, ampliando las diferencias preexistentes entre las provincias y ciudades más aventajadas por su ubicación territorial, su tradición cultural, y la disponibilidad de recursos económicos e institucionales y aquellas que no poseen capacidad propia para sustentar estrategias independientes de representación y de promoción externa. ${ }^{10}$

Sin embargo al momento de analizar experiencias concretas, los estudios son menos conclusivos y terminan, al igual que en la teoría de los escalamientos, relativizando el tipo de impacto al modelo o diseño institucional en el que se inscribe el proceso de integración regional. Una vez más el modelo de integración europeo es el que más ha avanzado en la decisión de asegurar la coordinación entre los distintos niveles de gestión, dando protagonismo a los poderes locales (Jones \& Keating, 1995), con reglas claras sobre las facultades y obligaciones delegadas, lo que asegu- 
ra en definitiva mayor accountability y transparencia entre los distintos niveles de gestión. Esta decisión no fue originaria sino que se plasmó en instancias formales con el tratado de Maastricht (1992), con la creación del Comité de las Regiones (de ahora en más CR). ${ }^{11}$ Con posterioridad y de manera creciente se fueron clarificando sus competencias en el proceso decisional, formalizando en el tratado de Ámsterdam (1998, art.162) la obligación de la Comisión Europea y el Consejo Europeo de consultar a esta nueva institución comunitaria sobre los temas regionales y sobre la manera en que se distribuyen los fondos comunitarios; y con posterioridad, se hizo extensiva esta obligación al Parlamento Europeo (Tratado de Lisboa, 2007).

Esta participación no se restringió a la esfera supranacional; sino que abarcó también la apertura de oportunidades a nivel nacional. Algunos países -en su mayoría de organización federal- decidieron incluir, entre otras cosas, a representantes regionales como parte de su comitiva nacional en el Consejo de Ministros y de esta manera unificar las distintas visiones existentes en la llamada preferencia nacional de las autonomías subnacionales. ${ }^{12}$ De la misma manera, las propias subregiones, buscaron asegurarse una mayor accountability e influencia (lobby) sobre la burocracia europea y sus propios representantes nacionales estableciendo, según sus posibilidades una oficina de gestión internacional en Bruselas (Aldecoa Luzarraga, 2009; Noferini, 2010). Sin embargo, en la actualidad esta práctica parece estar perdiendo atractivo, y las regiones y ciudades con mayor poder de presión vuelven a orientar su prioridad hacia los gobiernos nacionales. ${ }^{13}$

Lo interesante de resaltar a los efectos de este artículo, es que estas distintas instancias de participación, abiertas directa o indirectamente por el proceso de integración europeo, lograron convertir en positivo un vínculo que, sin su presencia, es potencialmente negativo, como el que se genera entre el Estado nacional y las provincias en torno a la idea de autonomía. En este sentido, la experiencia europea pone en evidencia que bajo el paraguas de la Unión Europea se abren competencias y recursos adicionales que favorecen la cooperación entre ambas partes de la ecuación y con ellos ambas partes se benefician. Las regiones se benefician porque logran mayor voz y acceso a recursos y los gobiernos nacionales, por su parte, sacan provecho respecto a otros Estados nacionales porque aumenta su presencia y visibilidad en los distintos órganos comunitarios y a su vez porque a escala nacional, la participación de las regiones en la representación comunitaria refuerza la cohesión nacional.

Lo mismo ocurre con las soluciones provistas por las regiones para prevenir y reducir los impactos de la integración económica sobre la fragmentación o asimetrías internas generadas en el seno de los países miembros como entre los distintos Estados o regiones del bloque. A tal fin la UE creó dos fondos regionales: los fondos estructurales, que buscan disminuir las brechas de desarrollo entre regiones y se distribuyen siguiendo una lógica comunitaria ${ }^{14} ;$ y los fondos de cohesión, que se rigen bajo una lógica intergubernamental y buscan ayudar a los Estados miembros más atrasados a alcanzar el mismo nivel económico y social que el resto de los países a través de inversiones en infraestructura. Se trata de sumas elevadas, que en su conjunto totalizan el $40 \%$ del presupuesto europeo. 
Un modelo opuesto es el caracterizado por el NAFTA y el ASEAN, donde la intervención de las regiones en las decisiones del bloque está prácticamente ausente $\mathrm{y} /$ o está limitada a algunos países, como es el caso de los EE.UU. en el NAFTA. ${ }^{15}$ En su remplazo, el liderazgo regional lo ejercen los mercados globales, que en búsqueda de una mayor competitividad integran y dan participación en el proceso tan solo a aquellas provincias o ciudades que ofrecen ventajas comparadas en términos de recursos materiales y humanos y que generalmente están ubicadas en las fronteras lindantes con las economías pujantes. La inserción internacional de estas últimas y la exclusión del resto de las regiones y provincias que conforman el país de los beneficios de esta integración económica, generan una fragmentación interna y la pérdida de cohesión nacional, que termina por crear un clima de inestabilidad política y social. Esto es lo que ha sucedido en los años ' 90 con el surgimiento de movimientos antisistema en Chiapas, donde la sociedad en su conjunto mantiene un profundo sentimiento de exclusión social y desprotección por parte del Estado. También es probable que esta situación se reproduzca en el contexto asiático en el mediano y largo plazo, especialmente en países como China, cuando el sistema político reinante -caracterizado por su alta centralidad y autoritarismovaya perdiendo su capacidad de frenar y acallar estos movimientos de protesta e indignación que genera la exclusión y el aumento de la desigualdad interna.

Para achicar las asimetrías creadas entre los países y las regiones del NAFTA, el bloque fundó en 1994, año de su creación, el Banco de Desarrollo de América del Norte que cuenta con un reducido fondo de carácter intergubernamental, que hasta ahora no ha hecho más que mitigar las externalidades negativas -sociales y medioambientales- generadas por la apertura y que además demuestra serias dificultades para asegurar su funcionamiento y renovación de fondos en el tiempo (Kaiser, 2005).

A partir de esta revisión bibliográfica es posible responder a nuestro interrogante inicial, señalando que efectivamente toda decisión de derribar fronteras comerciales genera una activación de los actores subnacionales y una oportunidad para generar sus propias capacidades (redes) para vincularse con el exterior y mejorar su posicionamiento externo. Sin embargo, la literatura también advierte sobre los impactos que esta autonomía genera sobre las asimetrías y la coordinación de la gestión interna a nivel nacional. Y ejemplifica a través de casos y experiencias concretas de integración, los incentivos y mecanismos que los gobiernos disponen para reducir los impactos negativos y potenciar los positivos. A continuación, analizaremos cómo ha sido la intervención del Mercosur en el tema, respondiendo a los siguientes interrogantes: ¿En qué medida es un tema de interés y preocupación en la agenda de los gobiernos?, ¿qué espacios de participación y de influencia se abrieron a los gobiernos subnacionales en las decisiones regionales? y ¿qué recursos financieros se han ido creando para achicar las asimetrías y favorecer la cohesión nacional y regional hasta el momento? 


\section{El Mercosur: ¿a qué modelo de acercamiento subnacional se asemeja?}

Aun cuando el Mercosur se crea con el Tratado de Asunción (1992), el proceso de integración regional se inició en los años ' 80 de manera concomitante con la recuperación de la democracia y el agotamiento del modelo de sustitución de importaciones. Con el fin de consolidar las recientes democracias y de dar solución a la llamada crisis de la deuda externa los gobiernos de Argentina y Brasil firmaron en 1986 el Protocolo de Integración y Cooperación Económica (PICE). Este acuerdo de carácter bilateral hablaba de integrar las economías de ambos países a través de un modelo de complementación productiva, según el cual los gobiernos mantendrían su protagonismo en la selección de los sectores a integrar y en la aplicación gradual de los mecanismos necesarios. Es en este marco de cooperación argentino-brasilera cuando se habla, por primera vez, de cooperación transfronteriza y se crean los llamados comités de frontera como áreas privilegiadas para el desarrollo regional. ${ }^{16}$

Con la creación del Mercosur se da nuevos bríos a la integración regional, ampliando el número de países miembros y reformulando los alcances y los objetivos de la integración regional. ${ }^{17}$ Sin embargo, en términos de la activación subnacional se elimina toda mención explícita a la cooperación transfronteriza y de desarrollo de actores y redes locales. El desarrollo de las capacidades subnacionales y la descentralización de la gestión externa deja de ser una experiencia motorizada desde abajo, por las demandas y estrategias de la acción colectiva local y transnacional -como había sido la experiencia del Crecenea-Codesul en el periodo anterior ${ }^{18}$ para convertirse en uno de los vértices de las reformas estructurales diseñadas por las instituciones financieras internacionales y puesta en marcha por los ejecutivos nacionales en los años ' $90 .{ }^{19}$

El tema subnacional recién aparece en la agenda del Mercosur de manera tardía y como resultado de la movilización y activación de las ciudades e intendencias que se agruparon en las llamadas "Mercociudades"; mientras que las provincias y gobernaciones tuvieron en este primer momento un rol más colateral y marginal. Esta red de ciudades fue creada en 1995 por los principales centros urbanos del corredor comercial Sao Paulo-Buenos Aires, con el propósito de aunar esfuerzos y exigir mayor participación e información sobre las decisiones regionales. La respuesta del bloque a estas demandas fue la creación de una instancia de participación en la estructura institucional del Mercosur: la Reunión Especializada de Municipalidades e Intendencias (REMI), integrada por representantes de la Cancillería y de los gobiernos subnacionales con "la tarea de promover el diálogo y la cooperación entre las autoridades de nivel municipal de los Estados Partes del Mercosur, de manera de promover el bienestar y una mejor calidad de vida a los habitantes de las ciudades de la región" (fundamentación Resolución 90/00). Sin embargo, la ambigüedad y falta de claridad sobre los alcances y funciones de la misma deja en claras la ausencia de visión estratégica que tienen los gobiernos nacionales sobre qué pueden aportar los actores subnacionales al Mercosur (Ventura et al., 2004). 
Con anterioridad a la REMI, no existía espacio de expresión de los intereses subnacionales en el Mercosur. La única vía de participación que encontraban las provincias para elevar iniciativas que las beneficiaban o bloquear las que las perjudicaban era a través de la Comisión Parlamentaria Conjunta (CPC), órgano consultivo y originario de la estructura institucional del bloque. Efectivamente, la mayoría de los legisladores de la sección argentina provenían de provincias vinculadas con el Mercosur. Sin embrago, este canal de participación no fue de gran ayuda a este propósito por problemas vinculados con la dinámica y los procedimientos decisionales del bloque: la regla del consenso único, que impide el avance de cualquier iniciativa que tenga al menos la oposición de un legislador, por una parte ${ }^{20}$ y la falta de reglas de transparencia y accountability que aseguren una respuesta o seguimiento al desinterés demostrado por el GMC frente a cada una de las propuestas consensuadas por el CPC. ${ }^{21}$

Con el resurgir de un Mercosur "más social y productivo" una vez superada su profunda crisis (1999-2001), el tema subnacional reapareció con fuerza en la agenda de trabajo regional. Por primera vez los gobiernos del bloque hablan de la necesidad de reducir las asimetrías internas y de fortalecer la integración productiva a través de cadenas de valor que incorporen las ventajas comparadas de las provincias a un lado y otro de la frontera. Sin embargo, cabe resaltar que no se habla de las provincias o ciudades como actores en la toma de decisión, sino más bien como destinatarios de las políticas o de los recursos definidos a nivel nacional. Esto se refleja en los nuevos espacios de participación subnacional que se abren en la estructura institucional del bloque.

- El foro consultivo de municipios, estados federados, provincias y departamentos del MERCOSUR (FCCR)

Este espacio fue creado por el CMC en la Cumbre de Belo Horizonte (2004) con el fin de reemplazar y acallar el activismo que la REMI venía adquiriendo en sus tres años de funcionamiento y que prometía capacidad propositiva y visibilidad mediática. ${ }^{22} \mathrm{La}$ iniciativa provino del gobierno de Brasil y contó con el apoyo de los gobernadores (Salomón, 2010). Entre las razones para el apoyo de los gobernadores está, por una parte, la voluntad de recuperar el protagonismo como principales interlocutores del bloque y los gobiernos centrales. Por otro lado, señalan algunos autores, la dificultad de sostener la dimensión política de la integración y de trabajar en red debido a su ligazón estructural y directa con el territorio y a la interpretación de que la defensa del territorio es un conflicto de suma cero (Paikin \&Vázquez, 2008).

El mandato que se le dio a la FCCR fue, como ocurrió con anterioridad para el caso de la REMI, amplio y ambiguo: "propiciar la realización de una visión compartida sobre el desarrollo territorial en el marco de la integración (decisión 41/04)". Para ello se organizaron dos tipos de reuniones: una orientada a las ciudades "el Comité de Municipios" y otra a las provincias, "el Comité de Estados Federados, de Provincias y Departamentos". Si bien la idea era reunir a distintos 
actores subnacionales, la dinámica que se le imprimió a las reuniones terminó privilegiando la visión de los funcionarios nacionales. Así por ejemplo, en vez de priorizar la discusión sobre temas comunes a las regiones y problemas transfronterizos, las distintas visiones se estructuraron en torno a las secciones nacionales. En segundo lugar, la coordinación de cada una de estas secciones nacionales se mantuvo a cargo de los ejecutivos nacionales en vez de dejarlos, de manera rotativa, en manos de funcionarios provinciales, asegurándose así una mayor apropiación del debate por parte de los actores subnacionales. Por último, se dejó librada a cada sección nacional, la decisión de qué órgano o ministerio se ocuparía de la coordinación del tema; lo que en definitiva generó un desequilibrio institucional y terminó por dificultar el diálogo y la posibilidad de avanzar en consensos entre las distintas secciones nacionales (Rhi Sausi y Oddone, 2010). ${ }^{23}$

Uno de los pocos éxitos del FCCR ha sido la constitución de dos foros: el GAHIF y el Foro sobre Integración Productiva que cuentan con financiamiento de la Agencia Española y la Unión Europea respectivamente. El GAHIF fue creado en 2002 para dar fluidez y armonía al relacionamiento de las comunidades fronterizas entre los Estados miembros. En tal sentido, CMC encomendó al GAGIF que elaborara un estatuto de frontera que extendiese la calidad de "natural fronterizo" (para la residencia, estudio, trabajo y salud) a todos los pobladores de las zonas de frontera del Mercosul. Sin embargo, hasta la fecha los avances no lograron concretarse. Una vez más las dificultades se vinculan con la dinámica decisional del Mercosur: la oposición de Paraguay a una iniciativa de este tipo, lo cual impide la construcción del consenso y la falta de injerencia de los principales interesados en las reuniones, cuyo control y participación está en manos exclusiva de los ejecutivos (Rhi Sausi \& Oddone, 2010).

Frente a los obstáculos surgidos a nivel regional, el tema transfronterizo recobra protagonismo a nivel bilateral. En el año 2005, los presidentes de Argentina y Brasil, firmaron el Acuerdo sobre Localidades Fronterizas, que asegura la libre circulación de personas en virtud de la tarjeta de Tránsito Vecinal Fronterizo, crea un régimen de circulación de vehículos automotores de uso particular para los usuarios de la tarjeta y establece un régimen de tráfico vecinal fronterizo que exceptúa de la declaración y pago de gravámenes a la importación/exportación para uso personal. ${ }^{24}$ En el año 2011, se crea la Comisión de Cooperación y Desarrollo Fronterizo (CODEPRO) para activar, dinamizar y coordinar las propuestas de los grupos de trabajo y de los comités de frontera dejados en el olvido. Sin embargo, esta iniciativa está aún pendiente.

\section{- El Fondo de convergencia estructural del Mercosur (FOCEM)}

De todos los espacios de participación abiertos por el Mercosur, éste es sin dudas el más promisorio en términos de alcance y de impactos. Este fondo se creó en 2001 luego de la profunda crisis que hundió al MERCOSUR y amenazó con el abandono de los países más pequeños. Su propósito, en gran medida, fue compensar las asimetrías entre países y regiones que preexistieron al bloque pero que, a consecuencia de la modalidad de la integración y la falta de intervención pública, se fueron profundizando con el tiempo. 
Como su nombre lo sugiere, la propuesta del FOCEM busca reproducir la experiencia de los fondos estructurales de la Unión Europea que pretenden achicar las brechas de desarrollo de la región (ver ítem 1). Sin embargo, las decisiones adoptadas posteriormente por los gobiernos para su puesta en marcha amenazan seriamente sus resultados. La primera se refiere a la escasez de recursos disponibles, que apenas llegan a los 100 millones de dólares. La segunda, el abandono de los criterios y de la perspectiva regional para la colecta y distribución de fondos. En vez de ser la región la que promueve la cohesión interna, se opta porque sean los Estados más grandes los que ayudan a los más pequeños. De la misma manera, en lugar de priorizar los fondos a proyectos que involucren a más de un país, el criterio de distribución de los recursos toma a los Estados nacionales como destinatarios. ${ }^{25}$ En tal sentido, los principales beneficiados de estos fondos regionales son Paraguay y Uruguay; mientras que Brasil y Argentina, se erigen como sus principales aportantes.

Un segundo grupo de problemas deriva de la dinámica y los procedimientos elegidos para la selección de los proyectos a financiar por el FOCEM. Si bien los proyectos pueden ser propuestos por actores subnacionales, son los gobiernos nacionales los que evalúan si está dentro o no de las prioridades nacionales y siendo éste el caso, es la Cancillería y el Ministerio de Economía, quienes hacen su presentación formal y defensa ante los organismos regionales. En esta lógica intergubernamental quedan excluidos los actores no gubernamentales y organismos regionales, los cuales podrían aportar al proceso una mayor democratización y carácter regional, como es el caso del Programa Somos Mercosur, el Parlamento del Mercosur y/o el Foro Consultivo de Municipios, Estados Federales, Provincias y Departamentos del Mercosur (NUSO, 2010).

Un hecho que refleja en gran medida algunos de los inconvenientes señalados, es que buena parte de los proyectos de infraestructura física del Mercosur, que demandan grandes sumas e inversiones públicas y privadas, no están incluidos en la agenda del FOCEM sino en el marco del Plan para la Infraestructura de la Integración Sudamericana (IIRSA). Este es el caso de los tres corredores bioceánicos, hidrovía Paraguay-Paraná, Mercosur-Chile, y el eje Capricornio (Silveira, 2003).

Hasta aquí, el mapeo de los distintos espacios y recursos abiertos por el Mercosur a los actores subnacionales. En términos de su desarrollo o evolución histórica, la activación subnacional en el Mercosur se caracteriza como un proceso iniciado desde abajo, por la movilización de las ciudades y principales centros urbanos y no por los gobiernos provinciales o nacionales. En cuanto a sus alcances, el Mercosur se caracteriza por la proliferación de espacios de participación subnacional que, lejos de fortalecer la acción transnacional de las provincias se mantienen dentro de la lógica y del control de los actores nacionales. Para articularse con el exterior, las provincias privilegian los vínculos bilaterales a los espacios regionales abiertos por el Mercosur. A continuación, ilustramos esta tendencia, a través de la descripción de la actividad transnacional desarrollada por cada una de las provincias seleccionadas hasta el momento. 


\section{Los usos y las estrategias de acción colectiva regional ¿En qué medida las provincias argentinas han sacado provecho del Mercosur?}

Siguiendo la caracterización de Pekerman (2007) las redes y estrategias transnacionales de los actores locales pueden ser de distinta índole, dependiendo del motor de la integración. En este sentido, es posible identificar al menos tres tipos puros ideales: la acción colectiva de carecer administrativo, motorizada por actores públicos regionales; la promovida por los mercados globales o regionales y la generada por los propios actores locales (Ver cuadro $\mathrm{N}^{\circ} 1$ ). En las páginas que siguen, se describe y compara la experiencia de cada provincia, con el objetivo de identificar si existe o no un patrón nacional; y en caso de que no sea así, contribuir al debate de cuáles son los factores que explican su diferencia.

\section{- El caso de la provincia de Santa Fe}

Esta provincia ha venido participando activamente en los espacios de actuación regional desde comienzos del proceso de integración en los años ` 80 y lo sigue haciendo en la actualidad. En lo que hace a los espacios creados desde arriba (top down), Santa Fe asegura su presencia en ambos órganos de discusión política del FCCR enviando representantes al comité de gobernadores y de las ciudades, aunque en este último caso la presencia se reduce tan sólo a las grandes ciudades, como Santa Fe, Rosario y Rafaela. ${ }^{26}$ De manera más reciente, la provincia también ha incursionado en el FOCEM a través de la presentación de un proyecto para reparar 72 escuelas del norte de la provincia que fue avalado por el gobierno nacional y posteriormente aprobado a escala regional. A pesar de ello, los funcionarios de la provincia no consideran a estos espacios como relevantes sino más bien simbólicos y de relativa efectividad.

En cuanto a las estrategias motorizadas por los mercados, la región es visualizada por los distintos actores locales como un espacio económico que ha venido potenciando la capacidad e inserción productiva de la provincia a través de las exportaciones de sus manufacturas primarias como industrializadas. En los hechos, la región en general, y Brasil en particular, se ha constituido en el principal destino de sus productos. Si bien con anterioridad las grandes empresas estaban internacionalizadas, la novedad que introduce el Mercosur es la posibilidad de conformar redes de producción y comercialización con empresas de otros países (las llamadas "multilatinas"). Para estas grandes empresas, la región es el primer paso para salir a conquistar mercados globales, sumando y complementando capacidades y recursos. Para la provincia, estas redes empresariales, no sólo permiten atraer capitales e inversiones, sino también generar fuentes de trabajo e introducir nuevos conocimientos e innovación tecnológica, fortaleciendo las Pymes a través de los encadenamientos productivos. Los casos más conocidos de empresas brasileñas que han invertido en la provincia son la productora de acero Gerdau y la exportadora de carnes Fribou.

Pero más allá de las oportunidades abiertas por la región y por el mercado, el gobierno de la provincia y los de las ciudades más importantes, han venido desarrollando una prolífera acción colectiva transnacional. Entre los casos más renombra- 
dos se encuentra la red Crecenea-Codesul, la red de las Mercociudades la "región centro"; y la red ATACALAR, a la que se ha incorporado de manera reciente. ${ }^{27} \mathrm{En}$ el primer caso, se trató de una red transfronteriza, integrada en el año 1986 entre dos redes de alcance interprovincial preexistentes: la primera, una red argentina, CRECENEA-Litoral, creada en los ' 80 entre las provincias de Chaco, Misiones, Corrientes, Entre Ríos, Formosa y Santa Fe; y la segunda, de origen brasileño -CODESUL (Conselho de Desenvolvimiento e Integracao)- formada en los años `60 entre los gobernadores de los Estados de Rio Grande Do Sul, Santa Catarina y Paraná. ${ }^{28}$ El objetivo de esta confluencia ha sido la de profundizar el vínculo y los intercambios de ideas sobre problemas comunes y posibles soluciones. Desde su origen, esta red, liderada por los ejecutivos provinciales y estaduales jugó un papel muy importante en el desarrollo de las políticas de cooperación transfronteriza y en la construcción de la integración regional (Vigevani, 2004).

A diferencia de Crecenea-Codesul, Mercociudades es una red liderada por los municipios e intendencias y su creación es posterior a la creación del Mercosur. Por la Argentina participaron las capitales de La Plata, Córodba, Buenos Aires; por la provincia de Santa Fe, el liderazgo estuvo a cargo de la ciudad de Rosario. Distintos factores contribuyeron a su conformación como la influencia de la experiencia europea de las "Eurociudades"; los acuerdos de cooperación técnica que proliferaron en los años ‘90 entre las ciudades europeas y las del Mercosur; y el apoyo mediático que lograron en las llamadas cumbres antiglobalización, como la Cumbre de los Pueblos que tuvo lugar en Porto Alegre, en ocasión del ALCA. Sin embargo, como lo señala la misma acta de creación de las Mercociudades, su principal motivación fue aunar fuerzas y recursos en demanda a los gobiernos del bloque de mayor participación y acceso a la información en temas transfronterizos que los afectaban directamente y que hasta entonces eran decididos en reuniones cerradas por las burocracias nacionales de los Ministerios de Relaciones Exteriores. ${ }^{29}$ Sin embargo, una vez constituida esta red hizo importantes aportes a la consolidación institucional del Mercosur, como la creación de la REMI (ver punto 2) y la formación de programas como Somos Mercosur.

Por su parte, la Región Centro es una red de provincias argentinas que se crea en el año 2006 entre Santa Fe, Córdoba y Entre Ríos. Si bien en ella no se incluye ningún gobierno intermedio del exterior, su origen está motivado por la necesidad de potenciar la competitividad y las capacidades de promoción comercial de la subregión en las negociaciones externas con otros países, como China, o en foros internacionales como la OLAGI ${ }^{30}$ Por ello entre sus principales actividades está la de organización y participación conjunta en misiones comerciales, rondas de negociaciones, ferias internacionales; como también busca capacitar e intercambiar experiencias entre empresas; hacer inteligencia comercial conjunta y estudios sobre demandas y ofertas exportables hacia China.

\section{- El caso de Córdoba}

$\mathrm{Al}$ igual que Santa $\mathrm{Fe}$, esta provincia y sus ciudades han sido una de las principales beneficiarias de la integración económica del Mercosur. La creación de 
mercado protegido (unión aduanera) y la vigencia de un régimen de comercio administrado en el sector automotriz, contribuyó a fortalecer el sector de PyMES que concentra entre el 80 y el $90 \%$ del tejido de la provincia. La fuerte articulación con Brasil, principal destino de sus exportaciones, va más allá de las actividades productivas y comerciales y de manera reciente se ha extendido al ámbito financiero, con la obtención de préstamos del Banco Nacional de Desarrollo Económico y Social de Brasil (BNDES) para la construcción de un gasoducto.

Sin embargo, a diferencia de la provincia de Santa Fe, la acción colectiva transfronteriza es más diversificada y reconoce una activa participación del actor privado. En efecto, en Córdoba las negociaciones internacionales no están centradas en el Estado sino que hay un fuerte liderazgo privado -integrado no sólo por empresas y think tanks sino también por universidades-, que acompaña y asiste al sector público en sus distintas actividades de promoción comercial (Botto \& Scardamaglia, 2011). Una segunda novedad introducida por esta provincia en términos de acción colectiva es su activa participación en redes globales como la Red de Organizaciones Regionales de Promoción Comercial (RTPO, en su sigla en inglés) ${ }^{31}$ y la Organización Latinoamericana de Gobiernos Intermediarios (OLAGI). En cada una de estas redes globales, Córdoba se posiciona y ejerce un rol de mediadora y transmisora de experiencias y conocimientos de lo global a lo nacional y viceversa. ${ }^{32}$

Esto se refleja en redes nacionales tan diferentes como la región centro y la red ATACALAR, de la que la provincia es miembro. La primera, como señalamos anteriormente, es una red de carácter propositivo y cuyo interlocutor son los gobiernos o empresas globales. ${ }^{33}$ La segunda, ATACALAR, es una red defensiva conformada por todas las provincias argentinas que buscan potenciar su presencia internacional reclamando al ejecutivo nacional las facultades y recursos; en ella, el rol de Córdoba es el de asistir a las más pequeñas e inexpertas.

En cuanto al uso de los canales y espacios de articulación vertical abiertos por el Mercosur, Córdoba participa tan solo de algunos de ellos en la actualidad. Si bien ha tenido un papel fundamental en la creación de la REMI, como una de las ciudades más activas de la red de Mercociudades, hoy se manifiesta desinteresada en participar del FRRC y tampoco busca mayor visibilidad en el FOCEM. El único espacio regional que esta provincia considera relevante es el Programa Cuatro Motores del Mercosur, creado a semejanza de su homónimo europeo. ${ }^{34}$ En esta red, que conforma junto a las provincias de Paraná (Brasil) Alto Paraná (Paraguay) Rivera (Uruguay), Córdoba se erige como líder y único representante de la Argentina. Esta red fue creada en el año 2009 y puesta en marcha en el 2011 y tiene como principal objetivo la promoción de la competitividad de sus empresas a través de la cooperación con su par europeo. Para la provincia, su principal beneficio es el de participar en proyectos específicos de cooperación descentralizada.

\section{- El caso de Buenos Aires}

Esta provincia comparte muchas de las características de las provincias anteriores en cuanto a la posición privilegiada y los beneficios económicos derivados de 
la integración de los mercados y la producción. En primer lugar, el comercio constituye uno de los principales motores de la internacionalización aunque en este caso, los productos industrializados concentran el $70 \%$ del total de exportaciones ( $51,7 \%$ de MOI y $18,4 \%$ de MOA). También en este caso, el Mercosur ampliado (con Chile, Venezuela y Bolivia) constituye el principal destino de la actividad comercial concentrando el 50\% de las exportaciones, de las que Brasil absorbe el $30 \%$ y Chile el $8,2 \%$. Por último, la actividad comercial derramó ventajas sobre otros tipos de negociaciones como las financieras y las inversiones, en las que de manera reciente se ha sumado la IED de capitales de Brasil y de Chile.

Sin embargo, lo llamativo de esta provincia es la escasa acción colectiva transnacional que desarrolla de manera individual y de manera conjunta con otras provincias o ciudades del país o del exterior. Esta provincia no participa ni ha tenido liderazgo alguno en redes público-privadas de carácter transfronterizo vinculadas directa o indirectamente con el Mercosur. De la misma manera, tampoco muestra en la actualidad un interés especial por participar en los espacios de intercambio y de distribución de fondos abiertos por el Mercosur.

\section{- El caso de Corrientes}

En virtud de su ubicación geográfica y de su perfil productivo, esta provincia no se beneficia de la integración comercial sino más bien de las actividades vinculadas con la integración transfronteriza. En efecto, el hecho de compartir sus fronteras con los tres países miembros del Mercosur (Brasil, Paraguay y Uruguay) a través de $700 \mathrm{Km}$. de frontera, la obliga a priorizar su agenda internacional hacia los temas vinculados con el uso y manejo de las fronteras, como ser el movimiento de personas y el uso compartido de los recursos naturales, entre otros..$^{35}$. Los beneficios materiales que trajo la conformación de un mercado ampliado para una provincia que no tiene producción para exportar son mínimos. En términos de atracción de IED y/o de radicación de empresas, el único caso exitoso ha sido, hasta ahora, una empresa brasileña para la producción de arroz. Merced a la cercanía y a las condiciones climáticas, esta empresa se radicó en la provincia en el año 1987 y como parte del paquete de cooperación transfronteriza del PICE (ver punto 2), pero recién se consolidó en el año 1995 en pleno apogeo comercial del Mercosur.

Estos hechos explican el desinterés o mala predisposición que siente la ciudadanía, en términos generales, hacia el Mercosur. Para ella, la cooperación generada en las áreas de frontera era una realidad desde antes de la creación formal del Mercosur; y los cambios introducidos para favorecer el intercambio comercial, si bien han favorecido a las grandes empresas en lo que hace a la libre circulación de bienes, también han generado mayores controles en lo que se refiere a la circulación de personas, empeorando la calidad de vida del ciudadano a pie. Lo mismo se visualiza en términos del uso de los recursos naturales compartidos; la competencia entre los países por atraer la IED en un mercado ampliado, obliga a los Estados a reducir los controles y a hacer caso omiso a la regulación prexistente, como ocurrió en el conflicto de las pasteras entre Corrientes y Uruguay, que terminó por antagonizar a las poblaciones de ciudades hermanas. 
En este sentido, y a diferencia de los casos anteriores, los gobiernos de las provincias y de las ciudades han buscado participar y sacar provecho de los distintos espacios y recursos institucionales del Mercosur, vinculados con la integración transfronteriza. Dos son las áreas de gestión internacional más desarrolladas por la provincia: la cooperación técnica descentralizada con las regiones y ciudades europeas, allí el Mercosur es uno de los canales privilegiados por Europa; y las obras de infraestructura. Respecto a estas últimas, los resultados están a la vista, la aprobación del proyecto para la construcción del puente Santo Tomé-São Borja, la construcción de la estación transformadora (ET) de Paso de Los Libres, que ya ha sido recientemente aprobada por el FOCEM ${ }^{36}$ y la elaboración para la construcción de la empresa hidroeléctrica de Garabí, en conjunción con la provincias de Misiones y el Estado brasileño de Río Grande do Sul.

Por último, y en términos de la construcción de la acción colectiva transnacional (canales bottom up), la provincia de Corrientes ha tenido un papel protagónico en la red Crecenea-Codesul que, como señalamos anteriormente, tuvo un papel fundamental en los inicios de la integración bilateral entre Argentina y Brasil. Entre sus contribuciones se encuentra: la firma del primer protocolo de integración fronteriza entre Argentina y Brasil, la creación de los Comités de Frontera y la creación de los Grupos de Trabajo de Integración Temática (GIT). ${ }^{37}$ Con el pasar del tiempo, el activismo de Crecenea-Codesul se fue opacando. Cuando se creo el Mercosur (1992) una de sus primeras iniciativas fue pedir a las cancillerías de Argentina y Brasil que activaran el Grupo de Trabajo Permanente de las fronteras creado por el Protocolo $\mathrm{N}^{\circ} 23$ y que había caído en desuso. La propuesta no acusó recibo de parte de la región y motivó a que fueran los propios gobernadores los que crearan un foro de gobernadores con distintos grupos de trabajo de integración temática (GIT). Sin embargo estos GIT nunca lograron resultados por la dificultad que encontraban para traducir sus mandatos en acciones concretas (Zubelzú, 2008). Sus únicos logros han sido la firma de acuerdos de cooperación con regiones y ciudades europeas, como la Xunta de Galicia, en 1998; la Conferencia de Regiones Periféricas y Marítimas de la Unión Europea, en 2000 y con la región de Murcia.

De manera más reciente, la provincia también contribuyó a crear la red ATACALAR, donde participa activamente, y que como señalamos antes, es una red horizontal y defensiva de alcance nacional formada por algunos gobiernos provinciales con el fin de compartir experiencias y demandas al poder ejecutivo. Por último, Corrientes es miembro de una nueva red, ZICOSUR, creada en 1997 por gobiernos subnacionales y nacionales de Argentina, Chile, Brasil, Paraguay, Bolivia; y más recientemente, Perú. ${ }^{38} \mathrm{Si}$ bien esta red se conformó casi como una réplica del Mercosur, en lo que hace a su entramado institucional; su razón de ser fue "defensivo", ya que las provincias y las regiones que la conformaban lo hicieron por sentirse excluidas del Mercosur y de sus beneficios que se distribuían tan solo entre las provincias que formaban su núcleo duro. (Colacrai, 2010). 


\section{- El caso de Chaco}

$\mathrm{Al}$ igual que en el caso de Corrientes, esta provincia visualiza a la integración comercial como un mercado ampliado a través del cual los beneficios que recibe son ínfimos e indirectos. Por su tamaño y perfil productivo, Chaco vive del mercado interno y sólo tiene algunos productos de exportación primaria -como el charqui, los porotos, la soja, el maíz y el extracto de quebracho- que exporta a terceros países. En términos de integración productiva, el único beneficio que la provincia obtuvo de la ampliación de los mercados productivos ha sido la radicación de empresas brasileñas y asiáticas -como la textil brasileña Santana o la de motos chinas, Ghiggeri- que se han instalado en las zonas fronterizas buscando reducir costos de fabricación en virtud de la exención o reducción de impuestos y servicios que les asegura el gobierno a cambio de generar fuentes de trabajo y transferencia tecnológica.

Siguiendo esta línea y con el objetivo de transformar y diversificar la estructura productiva, el gobierno provincial también proyecta obras de infraestructura que favorezcan las relaciones entre los distintos Estados subnacionales, NEA-NOA, y por supuesto los Estados del sur de Brasil, Paraguay, Uruguay, Bolivia, Chile. Entre estas obras se encuentra la puesta en valor del Puerto de Barranqueras, la Hidrovía Paraná-Barranqueras y la reactivación del ferrocarril Belgrano Cargas.

En dirección a esta estrategia, los actores públicos locales han venido desarrollando redes y acciones colectivas horizontales con otras provincias y Estados fronterizos en el marco de la región. Chaco es, sin lugar a dudas, la provincia que mayor número de alianzas ha construido en lo que va de la integración regional. $\mathrm{Al}$ igual que la mayoría de las provincias arriba mencionadas, participa de la red Crecenea-Codesul y ZICOSUR. Fruto de una ubicación geográfica privilegiada y de una agenda fuertemente orientada a la cooperación transfronteriza, el gobierno del Chaco tiene un especial interés en la red ZICOSUR y participa activamente en ella. ${ }^{39}$ Entre los mandatos de esta red, se encuentran tres áreas de política: comercio, infraestructura y cooperación transfronteriza; sin embargo, las mayores concreciones se observan en la agenda de infraestructura (Merlo, 2011).

Cuadro $N^{\circ} 1$ : Nivel de participación transnacional por provincias

\begin{tabular}{|c|c|c|c|c|c|}
\hline & Sta. Fe & Córdoba & Bs. As. & Corrientes & Chaco \\
\hline $\begin{array}{c}\text { Espacios creados } \\
\text { por bloque }\end{array}$ & alto & bajo & bajo & alto & medio \\
\hline $\begin{array}{c}\text { Espacios creados } \\
\text { por mercado }\end{array}$ & alto & alto & alto & bajo & bajo \\
\hline $\begin{array}{c}\text { Espacios creados } \\
\text { por actores } \\
\text { subnacionales }\end{array}$ & alto & alto & bajo & medio & alto \\
\hline
\end{tabular}




\section{A modo de conclusiones}

Las conclusiones que aquí se esbozan no pretenden ser exhaustivas ni conclusivas, sino contribuir a un debate en ciernes sobre el que se ha indagado poco hasta ahora, como es el de los impactos de la integración regional sobre la construcción de capacidades subnacionales. El análisis se reduce a un número acotado de provincias y al comportamiento de los actores públicos, dejando de lado los procesos de integración subterráneos que involucran a otros actores locales, como movimientos sociales y provincias no fronterizas, sobre los que la integración regional probablemente ejerce un impacto, aunque sea más indirecto.

Iniciamos el recorrido de nuestra investigación con una revisión de los distintos marcos teóricos y otras experiencias de integración concretas, de las que extrajimos una serie de respuestas clave a nuestro interrogante. La primera coincidencia entre los distintos enfoques teóricos, es que toda integración regional genera un impacto sobre los actores subnacionales, sea por la acción de los mercados o por la intervención de los Estados miembros del bloque. Esta activación subnacional puede analizarse en términos de cooperación/competencia con la diplomacia nacional; o bien, en términos de nuevas formas de acción colectiva transfronteriza (redes). Pero lo cierto es que de una u otra forma, se trata de crear capacidades autónomas, cuyos resultados en términos de políticas públicas son aún difíciles de asir, lo que obliga a focalizar las miradas sobre la formación de redes.

La segunda contribución que arroja, en este caso, la comparación entre distintas experiencias de integración habla de la importancia del alcance de la integración y el diseño institucional de la mismas al momento de determinar el tipo de redes creadas, tanto en los vínculos verticales (con la nación, con el bloque) como en los horizontales (con otras provincias o regiones dentro y fuera del país). A este respecto, un proceso de integración profunda tiende a generar redes de cooperación en todos los niveles, con claro predominio de los actores supranacionales; mientras los procesos de integración promovidos por los mercados y limitados a la esfera económica, tienden a promover la creación de redes horizontales, de alcance local, fragmentadas y lideradas por actores privados.

En esta dicotomía de tipos ideales, el Mercosur se ubica en una situación mixta o híbrida. En términos formales, la apertura en estos últimos años de espacios de participación y de recursos hacia las provincias, habla de un proceso creciente de instituciones regionales, más cercano a la experiencia europea que a la del NAFTA. Sin embargo, al analizar su dinámica interna se concluye que el carácter intergubernamental de las mismas y el control de las decisiones y de los recursos por parte de los funcionarios nacionales, lejos de promover la creación de capacidades autónomas, las inhibe.

Frente a este escenario regional, los actores subnacionales han venido desarrollando distintas estrategias de acuerdo a los recursos disponibles (ventajas comparadas) en cada una de ellos. Por una parte, están las provincias o ciudades más aventajadas - por su perfil productivo y su ubicación geográfica- que siguen estrategias diversificadas, activando redes propositivas públicas y privadas, verticales y horizontales. Por el otro, están las provincias menos aventajadas en lo económico 
-pero ubicadas estratégicamente en las fronteras del bloque- que privilegian los espacios abiertos por la región y participan de redes predominantemente públicas y defensivas. Por último, están las provincias que, como Buenos Aires, gozan de un perfil productivo diversificado desde antes del Mercosur, pero que están alejadas de toda frontera; en este caso, la estrategia dominante es la individual y prima el desinterés por los espacios y/o redes regionales.

De la evidencia analizada de los casos de estudio, se concluye que las oportunidades abiertas por la integración regional en el contexto sudamericano hasta el momento siguen, a pesar de los intentos por modificar esta tendencia, lideradas por los mercados. Es el mercado -regional y/o global- el que en definitiva potencia las capacidades y los recursos de las provincias con ventajas comparativas (en términos de productividad y cercanía) y marginan a aquellas que no las tienen. La consecuencia de esta modalidad de inserción internacional genera, como señala el enfoque de la paradiplomacia, un aumento de las asimetrías a nivel nacional; y promueve, al mismo tiempo, la desarticulación de las estrategias y la ausencia de mecanismos de transparencia y de accountability entre nación y provincia.

De allí que una mirada sobre la experiencia de la Unión Europea en el tema, permita sacar algunas recomendaciones para el futuro. Mas allá de las claras y evidentes diferencias que separan a la Unión Europea del Mercosur en términos de supranacionalidad y recursos disponibles, los espacios de participación subnacional abiertos por el primero demuestran una voluntad creciente por hacerlos protagonistas de las decisiones que los incumben; al mismo tiempo que se busca mitigar la defensa de intereses nacionales y particularistas, promoviendo temas y dinámicas regionales. En el caso del Mercosur, en cambio, las instituciones creadas por el bloque para promover las capacidades locales siguen estando controladas por actores nacionales y promueven la defensa de visiones e intereses nacionales. El corolario de esta "buena práctica" enseña que la existencia de espacios y de recursos regionales en manos de los interesados directos no sólo no resta poder a los gobiernos nacionales, sino que potencia los espacios de diálogo, coordinación y transparencia recíproca entre ambas esferas públicas.

\section{Referencias}

1. Quiero agradecer los generosos comentarios de Miryam Colacrai, Tulio Vigevani y Mariana Merlo.

2. En palabras de Colacrai (2010: 310) la dimensión económica está muy presente en la paradiplomacia; las provincias se mueven dentro del llamado paradigma del "estado comercialista" (Rosencrace, 1986) y cuando se evalúan sus resultados concretos se llega a la conclusión de que este accionar externo ha estado más cercano al marketing que a las realizaciones.

3. En gran medida, como señalan las especialistas, esta reforma constitucional vino a recoger y dar marco jurídico a la práctica que ya muchas provincias venían realizando (Colacrai \& Zubelzú, 2004).

4. En este sentido coincidimos con los estudiosos del tema, que señalan la dificultad de observar y medir impactos inmediatos y contrastables en términos de los nuevos procesos de internacionalización subnacional. En su reemplazo y de acuerdo a la literatura, que se desarrolla a continuación, caracterizaremos estas nuevas capacidades de internacionalización en términos de creación de redes transnacionales, contactos formales e informales, permanentes o ad-hoc, con entidades extranjeras públicas o privadas (Cornago, 2009). 
5. La ejemplificación de Van der Brande (2009) es ilustrativa al respecto. Mientras en 1957 (Tratado de Roma) solo 1 de los 6 miembros tenía estructura federal; hoy de los 27 Estados miembros, 3 tienen estructura federal (Austria, Bélgica y Alemania); 5 tienen fuertes elementos de federalismos (España, Italia, UK, Finlandia y Portugal); y en general TODOS los miembros han desarrollado una fuerte forma de descentralización /delegación interna. En esta tendencia, concluye el autor, han contribuido y mucho los fondos estructurales de la UE (el énfasis es nuestro).

6. La gobernanza multinivel analiza el vínculo entre tres niveles de gobierno que solo se dan en el proceso europeo: el nivel supranacional, el nacional y el subnacional además de la participación de actores estatales y no estatales (redes). Entre sus supuestos están, además, los de: 1) la competencia en la toma de decisiones es compartida por los actores de estos tres niveles; 2) que los actores y lugares de la toma de decisiones no están ordenados jerárquicamente y; 3) que los procedimientos son consensuales (y no mayoritarios) y por ende requieren de un proceso de negociación continuo y amplio (Kaiser, 2005).

7. En este modelo de gobernanza, los actores privados actúan más bien como agencia-el secretariadoanimando los proyectos que vienen desde la región, proveyendo expertise e intermediando demandas locales (Pekerman, 2005).

8. Este es por ejemplo el caso de la Asociación de Gobernadores Fronterizos, que busca mejorar las ventajas competitivas de la región a través de la cooperación en las áreas de seguridad, infraestructura, medioambiente, educación y energía (Schiavon, 2010).

9. Las relaciones fronterizas apuntalan el llamado triángulo de crecimiento entre territorios con distintos factores de producción y niveles de complementariedad (Jessop, 2002; Conargo, 2009).

10. La casuística es abundante al respecto: en el caso de la Unión Europea, los casos más conocidos son los de los Lander alemanes, las regiones vascas y catalanas en España. En el caso del NAFTA, los Estados y ciudades de frontera de México que lindan con la pujante economía de los Estados Unidos en contraste con los Estados del sur, como es el caso Chiapas en la península de Yucatán. En el este asiático, el contraste se sitúa entre las provincias litoraleñas de Tianjin, Shangdong y Gandgdong, altamente internacionalizadas en contraste con el resto de China que se mantiene en el pasado.

11. Con anterioridad a 1992, Salas (2004) identifica distintas instancias de participación subnacionales como: 1) la Conferencia de Poderes Locales y Regionales del Consejo de Europa (CPLRE) creada en 1961; las asociaciones de cooperación interregional creadas a partir de la década del 70 ( la Asociación de Regiones Fronterizas Europeas -ARFE-, la Conferencia de Regiones Periféricas y Marítimas de la CE -CRPM-; la Cooperación Interregional de las Regiones de naturaleza montañosa; la Asociación de Regiones de Capitales Nacionales, la Comunidad de Trabajo del Jura y la Asamblea de las Regiones de Europa. Todas ellas, señala el autor, contribuyeron a construir lazos horizontales y fueron un antecedente para la CR.

12. La literatura europea identifica los casos de España, Alemania y Bélgica. En el primero, se constituyó, en 1997, la Conferencia para Asuntos Relacionados con las Comunidades Europeas (CARCE) que sirve para promover, articular y resolver mecanismos de participación en conferencias sectoriales respectivas (Noferini, 2010). En Alemania, en cambio, por ley nacional se estableció que cualquier transferencia de competencia a la UE deberá ser aprobada por la mayoría de 2/3 de las cámaras del parlamento alemán (Kaiser, 2005). Sin embargo, es Bélgica quien más ha avanzado, permitiendo que los ministros de los Estados federales puedan representar a la nación y concluir acuerdos en su nombre (Bursens \& Deforche, 2009; Paquin, 2009).

13. Entrevista a Tulio Vigevani, enero 2012.

14. En este grupo existen distintas líneas de financiamiento, a saber: 1) los fondos europeos de desarrollo regional (FEDER); 2) los fondos sociales europeos (FSE); 3) los fondos europeos de orientación y garantía agrícolas (FEOGA) y; 4) el instrumento financiero de orientación de pesca (IFOP) (Medeiros, 2004).

15. En el caso de los EE.UU., el gobierno nacional ha abierto dos canales de participación indirecta: 1) el sistema de consultas que abre el representante de comercio (USTR) cada vez que se toma una medida relacionada con el NAFTA que pueda tener impacto directo sobre los Estados (este proceso está dirigido por un coordinador de asuntos estaduales de NAFTA que se contacta con la gobernación); 2) la participación en el Intergubernamental Policy Advisory Comitee (IGPAC). Sin embargo, ha rechazado toda inclusión directa en los comités del NAFTA, salvo en el Joint Public Advosiry de la Comisión 
Bilateral Mexicano-Estadounidense sobre cooperación medioambiental transfronteriza (Stuart, 2004). 16. Dentro de los 24 protocolos sectoriales firmados entre la Argentina y Brasil en el marco del PICE, el 29 de noviembre de 1988 se firmó el Protocolo №23 regional fronterizo con el propósito de abordar el desarrollo integrado de la región de fronteras mediante la participación más activa de esta región en el nuevo espacio económico ampliado.

17. Ya no serían los Estados los que definirían los alcances, modalidades y tiempos de la integración económica, sino los mercados y la libre competencia los que definirían el futuro y la capacidad de sobrevivir de cada uno de los sectores productivos a nivel nacional. La única excepción a esta regla fue en el sector automotriz, donde los gobiernos tuvieron una activa participación de promoción por considerarlo como la fuerza motora de la integración y el desarrollo productivo regional.

18. Si bien los presidentes de Argentina y Brasil reconocen en la Declaración de Iguazú (18/02/1995) la importancia de esta red transnacional como un instrumento "apropiado" para impulsar el desarrollo regional, no le hicieron lugar a ninguna de las propuestas por ella presentada.

19. En este sentido, la ley nacional 23.101 de promoción de exportaciones del año 1983 promovía la creación de estructuras especializadas públicas, mixtas o privadas en las provincias y preveía la creación de un fondo, se le daba a cada provincia recursos para poner en funcionamiento las áreas, adquirir el mobiliario necesario y capacitar a los funcionarios (Botto \& Scardamaglia, 2011).

20. Esto sucedió por ejemplo con el proyecto presentado por el legislador misionero Lozada, que proponía regular el tránsito aéreo de empresas brasileñas en las Cataratas de Iguazú, que fue rechazada por sus contrapartes brasileñas (Entrevista a Oscar Casal, Buenos Aires, diciembre, 2011).

21. Las dos únicas excepciones han sido las propuestas del CPC de incluir la cláusula democrática (1998) y la creación del parlamento Mercosur (2006). En ambos casos se trata de iniciativas sistémicas donde naturalmente no existe conflicto de interés ni oposición alguna.

22. Desde su primera reunión constitutiva en 2001 hasta la última de 2004, la REMI se reunió seis veces y entre sus propuestas al Consejo Mercado Común, la Secretaría del Mercosur y la Comisión de Representantes del Mercosur estaba la de crear el Foro de las Ciudades con un esquema alternativo de participación (Ventura et al., 2004).

23. Así por ejemplo, la sección argentina y paraguaya está representada por el Ministerio de Relaciones Exteriores mientras que la de Brasil lo está por la Presidencia y la Uruguaya, por el Congreso Nacional de Intendentes (Rhi Sausi \& Oddone, 2010, pág. 217).

24. Este acuerdo bilateral entró en vigencia el 02/07/2011 y contempla una de las demandas permanentes de las comunidades en las regiones fronterizas: la de asegurar que los vecinos de las ciudades de frontera puedan ejercer libremente el trabajo, oficio o profesión; acceder a la enseñanza pública y a la atención médica, en ambos lados de la frontera.

25. Hasta la fecha, tan solo 2,6 millones ( $1,8 \%$ del presupuesto inicial) han sido destinados a proyectos ubicados en zonas de frontera y en ambos casos fueron presentados y adjudicados a Uruguay (Sela, 2011: 7).

26. El resto de los municipios no participa del foro porque desconocen su existencia y no hay comunicación interna entre las ciudades (Ponencia de Germán Burcher, Secretario de Desarrollo, Innovación y Relaciones Internacionales de Rafaela, ex Subsecretario de Comercio Exterior provincial, reunión FLACSO/LATN /FES, Buenos Aires, 25/08/2011).

27. Santa Fe se ha incorporado a esta red en octubre de 2011 (para la descripción de la red, ver ítem Córdoba).

28. Esta red se crea en el año 1961 con el propósito de buscar soluciones conjuntas a los desequilibrios regionales en el país, en general; y el olvido de las provincias del sur, en particular.

29. Entrevistas a Rubén Geneyro, responsable de la Dirección de RR.II. de la CABA durante la Reunión FLACSO/LATN /FES, Buenos Aires, 25/08/2011.

30. La OLAGI es una red de gobiernos intermedios integrada por 14 países de América latina y por 150 gobiernos locales. Su principal función consiste en intercambiar y transferir experiencias y conocimientos entre los gobiernos subnacionales en materia de gestión pública internacional.

31. Esta red está conformada por agencias público-privadas de todo el mundo cuyo objetivo es promover el intercambio de experiencias y de know how entre países de América latina, las únicas agencias que participan en ella son ProCórdoba, ProMendoza, Bahía y Guanajuato (México). 
32. "Así por ejemplo, cuando se hizo la reunión anual de la RTPO en Córdoba, invitamos a todas las provincias, para que no quedara como un mérito de Córdoba sola. A esa reunión vinieron 15 provincias, entonces se hizo una actividad paralela". Ponencia de Viviana Arias, Gerente de Cooperación y Relaciones Internacionales, ProCórdoba en Reunión FLACSO/LATN/FES, Buenos Aires, 25/08/2011.

33. El rol de Córdoba en la Región Centro es representar y coordinar la participación de las tres provincias en las distintas actividades y foros, como por ejemplo ser sede de las escuelas "ESCOLAGI" -que capacitan funcionarios de toda América latina- en virtud de la alta concentración de universidades (29) en la región.

34. La red europea existe desde 1988 y la forman Baden-Württemberg, de Alemania; Lombardía, de Italia; Rhône-Alpes, de Francia y Cataluña, de España y busca contribuir a la construcción de Europa a través de proyectos innovadores y por medio de intercambios universitarios, científico-culturales y económicos.

35. En la actualidad sus principales acciones internacionales están vinculadas con lograr la conexión sobre el Río Uruguay a través del Puente Alvear-Itaquí; lidiar con los problemas de la isla de Apipé y fortalecer la participación de los actores subnacionales en el marco Crecenea-Codesul. Ponencia de María Gabriela Basualdo, Directora de Relaciones Internacionales, Gobierno de Corrientes, en Reunión FLACSO/LATN/FES, Buenos Aires, 25/08/2011.

36. Vínculo de Interconexión en 132 kv. ET Iberá-ET Paso de los Libres Norte, aprobado por Decisión $\mathrm{CMC} \mathrm{N}^{\circ}$ 03/10, cuyo organismo ejecutor es la Subsecretaría de Energía del Ministerio de Obras y Servicios Públicos de la Provincia de Corrientes, por un monto total de USD 19.057.519,17. Los recursos FOCEM aplicados a este proyecto alcanzan el monto de USD 13.116.511. Este proyecto tiene como fin contribuir a la mejora de la oferta de energía regional y la calidad de servicio a usuarios finales, potenciando la radicación de inversiones mediante el fortalecimiento del Sistema de Transmisión de $132 \mathrm{kw}$ en la zona de influencia de Iberá y Paso de Los Libres, así como su interconexión con Uruguayana, Brasil.

37. En los hechos, la provincia de Corrientes fue sede de uno de los primeros Comités de Frontera, el de Paso de los Libres-Uruguayana, que se creó en 1989 junto con el de Puerto Iguazú-Foz de Iguazú, y con posterioridad se creó el de Bernardo de Irigoyen-Cerqueira. En cuanto a su operatividad, los estudiosos del tema coinciden en señalar su irrelevancia dada su incapacidad para lograr resultados concretos. En gran medida, señalan, ello es consecuencia del control que ejercen las autoridades del ejecutivo nacional sobre sus decisiones y recursos (Recondo, 1991); mientras que los actores locales tienen una participación simbólica en las decisiones.

38. A través de la incorporación de los departamentos de Puno, Arequipa, Moquegua y Tacna (Merlo, 2011).

39. Hacia fines de 2011, la presidencia del Foro recayó en el gobierno de esta provincia (www.zicosur. gov.ar).

\section{Bibliografía}

F. ALDECOA LUZARRAGA(2009), “Aproximaciones a la paradiplomacia. Las regiones como actores de la política europea: Las aportaciones del Tratado de Lisboa", en Z. ZARAOUI, Regionalización y Paradiplomacia. La política internacional de las regiones, México, Montiel y Soriano Editores.

J. BERTRANOU (2008), "Introducción", en E. IGLESIAS, Las provincias argentinas en el escenario internacional. Desafios y obstáculos de un sistema federal, 1ra. edición, Buenos Aires, Programa de las Naciones Unidas para el Desarrollo - PNUD.

J. BLANES SALAS (2009), "Sub-State Diplomacy in Mexico", en D. CRIEKEMANS (2010), Regional Sub-State Diplomacy Today, Leiden, Martinus Nijhoff Publishers.

M. BOTTO y V. SCARDAMAGLIA(2011), "Globalización y descentralización: la internacionalización del policy making en las provincias argentinas". Ponencia presentada en X Congreso Nacional de Ciencia Política, organizado por la Sociedad Argentina de Análisis Político y la Universidad Católica de Córdoba, Córdoba, del 27 al 30 de julio.

M. BOTTO y V. SCARDAMAGLIA (2012), “Creando capacidades: las negociaciones económicas 
internacionales y las provincias argentinas: ¿un nuevo rol para el sector privado?”, Documento de trabajo FLACSO/LATN/ FES.

P. BURSENS \& J. DEFORCHE (2009), "Going beyond paradiplomacy? Adding historical institutionalism to account for regional foreign policy competences", en D. CRIEKEMANS (2010), Regional Sub-State Diplomacy Today, Leiden, Martinus Nijhoff Publishers.

S. CLARKE (2000), "Regional and transnational discourse: the Politics of Ideas and Economic Development", en International Journal of Economic Development, 2, 2.

M. COLACRAI y G. ZUBELZÚ (2004), "Las vinculaciones externas y la capacidad de gestión internacional desplegadas por las provincias argentinas en la última década. Una lectura desde las relaciones internacionales", en $A$ dimensao subnacional e as relaçoes internacionais, ed.Sao Paulo, UNESP, EDUC, EDUSC.

M. COLACRAI (2010), "El tejido de relaciones bilaterales desde el ámbito subnacional. Desarrollo de una innovadora interdependencia entre la Argentina y Chile", en L. MAIRA, La Política Internacional Subnacional en América Latina, Buenos Aires, Libros del Zorzal.

N. CORNAGO (2009), "On the Normalization of Sub-State Diplomacy", en D. CRIEKEMANS (2010), Regional Sub-State Diplomacy Today, Leiden, Martinus Nujhoff Publishers.

D. CRIEKEMANS (2010), Regional Sub-State Diplomacy Today, Leiden, Martinus Nujhoff Publishers.

B. HOCKING (2000), "Vigilando la 'frontera': globalización, localización y capacidad de actuación de los gobiernos no centrales", en ALDECOA \& KEATING, Paradiplomacia: Las relaciones internacionales de las regiones, Madrid, Marcial Pons.

V. IGLESIAS (2008), "Las provincias y su gestión en el área de comercio exterior. Diagnóstico y análisis del caso argentino", en E. IGLESIAS, Las provincias argentinas en el escenario internacional. Desafios y obstáculos de un sistema federal, 1ra. edición, Buenos Aires, Programa de las Naciones Unidas para el Desarrollo - PNUD.

B. JESSOP (2002), “The political economy of scale”, en PECKERMAN and SUM (eds.), Globalization, regionalisation and cross broader regions, New York, Palgrave, Houndsmills.

B. JONES and M. KEATING (eds.) (1995), The European Union and the regions, Oxford, Clarendon Press.

J. JORDANA, Ch. VOLPE MARTINCUS \& A. GALLO (2010), "Export Promotion Organizations in Latin America and the Caribbean: an Institutional Portrait", IDB Working Paper Series $\mathrm{N}^{\circ}$ IDPWP-198, agosto.

R. KAISER (2005), "Sub-state governments in International arenas: paradiplomacy and multi-level governance in Europe and North America", en G. LACHAPELLE \& S. PAQUIN (eds.), Mastering Globalization. New sub-states'governance and strategies, New York, Routledge.

M. KEATING (2000), "Regiones y asuntos internacionales: motivos, oportunidades y estrategias", en ALDECOA \& KEATING, Paradiplomacia: Las relaciones internacionales de las regiones, Madrid, Marcial Pons.

J. KINCAID (2000), "La competencia internacional de los Estados Unidos y sus gobiernos locales", en ALDECOA \& KEATING, Paradiplomacia: Las relaciones internacionales de las regiones, Madrid, Marcial Pons.

G. LACHAPELLE \& S. PAQUIN (2005), "Introduction”, en G. LACHAPELLE \& S. PAQUIN (eds.), Mastering Globalization. New sub-states'governance and strategies, New York, Routledge.

M. MEDEIROS (2004), "Unidades subnacionais e Integraco Europeia: O caso Do comité das Regioes", en VIGEVANI et al., A dimensao subnacional e as relacoes Internacionais, Sao Pablo, Educ/Unesp/ Edusc.

M. MERLO (2011), "Las Relaciones Internacionales de los Actores Subnacionales: Una estrategia de Acción en el Nuevo Orden Mundial. Los casos de CRECENEA/CODESUL y ZICOSUR”. Tesis de Maestría de la Maestría en Relaciones Internacionales, Buenos Aires, Universidad del Salvador.

A. NOFERINI (2010), "The participation of sub-national governments in the Council of the EU: some evidence from Spain", presentado en desayuno de trabajo en FLACSO-Argentina, 25 de agosto.

NUSO (2010), Resumen Taller Internacional de Cohesión social, integración regional y desarrollo en América Latina y el Caribe realizado el 8 de noviembre de 2007, Buenos Aires, Argentina. 
S. PAQUIN (2009), "Federalism and compliance with international agreements: Belgium and Canada compared”, en D. CRIEKEMANS (2010), Regional Sub-State Diplomacy Today, Leiden, Martinus Nijhoff Publishers, 2010.

D. PAIKIN y M. VÁZQUEZ (2008), “¿Paradiplomacia en el MERCOSUR? Incentivos y barreras a la participación de los actores subnacionales en el acuerdo regional”, en Anuario de la Integración Regional de América Latina y el Gran Caribe, año 2008-2009.

M. PEKERMAN (2005), "Constructor of New Territorial Scales: A framework and case Study of Eulogio Cross-Border Region", en Regional Studies Vol 4, 1.2.

G. RECONDO (1991), "Realidad y futuro de los Comités de Frontera", Documento de Trabajo. IDIAL, $N^{\circ} 4$, Asunción, Instituto Paraguayo para la Integración de América Latina.

J. L. RHI SAUSI \& N. ODDONE (2010), “Cooperación e integración transfronteriza en el MERCOSUR: el caso de la Triple Frontera entre Argentina, Brasil y Paraguay”, en L. MAIRA (ed.), La Política Internacional Subnacional en América Latina, Buenos Aires, Libros del Zorzal.

R. ROSENCRACE (1986), The Rise of the trading state. Commerce and conquest in the modern world, New York, Basic Books.

R. RUSSELL (2010), "El estado nación y los actores gubernamentales no centrales: una relación complementaria", en L. MAIRA, La Política Internacional Subnacional en América Latina, Buenos Aires, Libros del Zorzal.

M. SALOMÓN (2010), "El Foro Consultivo de Municipios, Estados Federados, Provincias y Departamentos del Mercosur en el contexto de la Política Exterior Brasileña”, en E. IGLESIAS y C. GASOL VARELA, El rol de los gobiernos subnacionales en los procesos de integración regional, Argentina, CARI/CEBRI.

Sistema Económico Latinoamericano y del Caribe -SELA (2011), La Integración Fronteriza en el Marco del Proceso de Convergencia de América Latina y El Caribe, Caracas, Secretaría Permanente del SELA.

J. SCHIAVON (2009), "Sub-State Diplomacy in Mexico", en D. CRIEKEMANS (2010), Regional Sub-State Diplomacy Today, Leiden, Martinus Nijhoff Publishers.

J. P. SILVEIRA (2003), Herramienta de trabajo para el diseño de una visión estratégica de la integración fisica sudamericana. Iniciativa para la Integración de la Infraestructura Regional Suramericana -IIRSA-, Caracas, Venezuela. Disponible en línea: http://www.iirsa.org/BancoMedios/ Documentos\%20PDF/cde4_caracas03_vesa.pdf

A. M. STUART (2004), "Regionalismo e democracia: o surgimento da dimensão subnacional na Union Europea" en T. VIGEVANI et al., A dimensão subnacional e as relações internacionais, Sao Paulo, Edusc.

L. VAN DEN BRANDE (2009), “A practitioner's perspective: sub-state diplomacy today”, en D. CRIEKEMANS (2010), Regional Sub-State Diplomacy Today, Leiden, Martinus Nijhoff Publishers. D. VENTURA, M. RATTON SANCHEZ, M. BOTTO, M. VAZQUEZ, R. GENEYRO (2004), Informe "Participação da sociedade civil e dos governos locais no Mercosur". Secretaria Administrativa del MERCOSUR, Diciembre.

T. VIGEVANI (2004), "Historia da integração latina americano: MERCOSUL e questões Subnacionais", en T. VIGENANI et al., A dimensão subnacional e as relações internacionais, Sao Paulo, Edusc.

G.ZUBELZÚ (2008), "El diseño institucional y los perfiles de gestión externa de las provincias argentinas", en E. IGLESIAS, Las provincias argentinas en el escenario internacional. Desafios y obstáculos de un sistema federal, Buenos Aires, Programa de las Naciones Unidas para el Desarrollo - PNUD.

Recibido: 14/02/12. Aceptado: 25/06/12.

Mercedes Botto, "Integración regional y actores subnacionales. El caso del Mercosur". Revista Temas y Debates. ISSN 1666-0714, año 17, número 25, enero-junio 2013, pp.83-106. 